\title{
NORMAS INTERNACIONAIS DE EDUCAÇÃO CONTÁBIL PROPOSTAS PELO INTERNATIONAL ACCOUNTING EDUCATION STANDARDS BOARD ${ }^{1}$
}

\section{INTERNATIONAL EDUCATION STANDARDS PROPOSED BY THE INTER- NATIONAL ACCOUNTING EDUCATION STANDARDS BOARD}

\author{
Fellipe André Jacomossi ${ }^{2}$ \\ Doutorando em Ciências Contábeis pela Fundação Universidade Regional de Blumenau (FURB) \\ fellipejacomossi@gmail.com \\ Vania Tanira Biavatti \\ Doutora em Ciências Sociais pela Pontifícia Universidade Católica de São Paulo, PUC/SP \\ Professora Titular da Fundação Universidade Regional de Blumenau (FURB) \\ vania@furb.br
}

\begin{abstract}
RESUMO
Objetivo: Investigar, sob a ótica dos profissionais, pesquisadores e professores de contabilidade, como as Normas Internacionais de Educação propostas pelo IAESB podem influenciar o ambiente nacional de educação contábil.

Fundamento: $O$ resultado de uma internacionalização dos padrões de educação voltados para o ensino contábil pode gerar diversos impactos na formação e atuação dos contadores, nos mais diversos territórios, como alterações nas diretrizes curriculares, melhorias nas habilidades interpessoais, e ainda, mudanças nos requisitos de entrada nos cursos, de experiência prática e desenvolvimento profissional contínuo.

Método: Realizou-se uma pesquisa de cunho descritivo, com procedimento de pesquisa de levantamento, realizado por meio de um instrumento utilizado ora como questionário, ora como roteiro de entrevista estruturada, elaborado com base na literatura e no Handbook of International Education Pronouncements do IAESB. Trata-se de um estudo qualitativo com a utilização da técnica de triangulação de dados.
\end{abstract}

Resultados: A partir da análise documental, descreve-se as especificidades de cada uma das IES, bem como constata-se sua abordagem principle based standards, possibilitando que cada jurisdição adapte as IES as suas particularidades regionais. Por meio da análise da perspectiva dos participantes, observou-se maior similaridade nas concepções referentes às IES 2, IES 3, IES 6 e IES 7, em contrapartida, os posicionamentos frente as IES 1, IES 4 e IES 5, apresentaram-se heterogêneas.

\footnotetext{
${ }^{1}$ Artigo recebido em: 31/03/2017. Revisado por pares em: 05/05/2017. Reformulado em: 12/05/2017. Recomendado para publicação em: 12/05/2017 por Dimas Barreto de Queiroz (Editor Adjunto). Publicado em: 14/06/2017. Organização responsável pelo periódico: UFPB.

2 Endereço: Antônio da Veiga, 140 - Vila Nova - Blumenau, SC, 89010-971.

DOI: http://dx.doi.org/10.18405/recfin20170304
} 
Contribuições: Ao relacionar as Normas Internacionais de Educação Contábil frente às influências identificadas na perspectiva dos investigados, constatou-se possíveis influências de cada uma das IES no ambiente nacional de educação contábil, delineando-se contribuições em três perspectivas distintas: teórica, prática e social.

Palavras chave: International Accounting Education Standards Board. Normas Internacionais de Educação Contábil. Internacionalização do ensino contábil. IAESB. IES.

\begin{abstract}
Objective: Investigating, from the perspective of professionals, researchers and accounting teachers, how the International Education Standards proposed by the IAESB can influence the national accounting education environment.
\end{abstract}

Background: The result of the internationalization of education standards focused on accounting education can generate several impacts on the training and performance of accountants in different territories, such as changes in curricular guidelines, improvements in interpersonal skills, and changes in entry requirements in courses, practical experience and continuous professional development.

Method: A descriptive research was conducted with a survey research procedure, using an instrument used as a questionnaire, or as a structured interview script, based on the literature and IAESB Handbook of International Education Pronouncements. Also, this is a qualitative study using the data triangulation technique.

Results: Based on this document analysis, the specifics of each of the IES have been described, and yet, it was found that its approach is principle-based standards, allowing each jurisdiction to adapt the IES in its regional peculiarities. By analyzing the perspective of the participants, there was greater similarity in the concepts related to IES 2, IES 3, IES IES 6 and 7, however, the prospects facing the IES 1, IES IES 4 and 5, showed up heterogeneous.

Contributions: By relating the international education standards with the influences identified from the perspective of professionals, researchers and accounting professors, it was found possible influences of each IES in the national accounting education environment, outlining contributions in three different perspectives: theoretical, practical and social.

Keywords: International Accounting Education Standards Board. International Education Standards. Internationalization of accounting education. IAESB. IES.

\title{
1 INTRODUÇÃO
}

A contabilidade contemporânea está mudando rapidamente, seu alcance geográfico é global e a tecnologia desempenha um papel cada vez mais proeminente neste fenômeno. Do mesmo modo, a natureza cada vez mais internacional dos negócios tem sido amplamente observada na literatura e as relações internacionais estão se expandindo e mudando em âmbito mundial (Abbasi, 2013).

O panorama educacional não é diferente. Anova geração de estudantes chega cada vez mais relacionada à tecnologia e, portanto, menos paciente com métodos tradicionais de ensino. Todas estas mudanças estão ocorrendo enquanto muitos requisitos e programas de graduação e pós-graduação em contabilidade permaneceram constantes (Abbasi, 2013).

De um modo geral, o ensino em contabilidade continua focado nas técnicas e habilidades da prática contábil (Boyce, 2004). Cada vez mais as Instituições de Ensino Superior concentram-se em preparar o aluno para o mercado de trabalho e atender as necessidades e demandas das organizações por profissionais com conhecimentos técnicos (Saravanamuthu \& Tinker, 2002).

No entanto, o ensino realizado por meio de protocolos de procedimentos que visam atender a tais demandas, restringe a capacidade do aluno a se adequar a novas lógicas que vão se inserindo no seu cotidiano. O ensino deve ser voltado para o desenvolvimento de habilidades e competências 
para além da técnica, caso contrário, se a lógica do processo for alterada, estes indivíduos não conseguirão adaptar-se.

A reforma na educação contábil precisa ir muito além da agenda de reformas consideradas pelos órgãos profissionais, deve-se ensinar e aprender outside the circle, e dessa maneira, tornar o ensino em contabilidade relevante em seu contexto social, histórico, assim como relevante para vivência dos próprios alunos (Boyce, 2002, 2004).

A aplicação das normas contábeis deve abranger o impacto da internacionalização dos negócios em seus relatórios e demonstrações contábeis, assim como no auxílio à tomada de decisão dos gestores. Ocorre que os esforços voltados a esta harmonização se deparam com diferenças na aplicação destas normas em países distintos, originadas também de diferenças na própria educação e qualificação dos contabilistas (Howieson, 2003).

Apesar dos indivíduos e instituições possuírem uma visão de mundo baseadas em suas próprias culturas, tradições e costumes, o IAESB visa a implementação de padrões educacionais voltados à contabilidade nas diversas instituições membros da IFAC, propondo assim, um sistema educacional convergente em todos os territórios. Esta lógica é derivada das Normas Internacionais de Contabilidade, as chamadas International Financial Reporting Standards (IFRS), assim como as International Standards on Auditing (ISA), ou seja, as Normas Internacionais de Auditoria, que os profissionais de contabilidade e as organizações em torno do mundo passaram a adotar tais práticas internacionais, em detrimento de práticas nacionais tradicionais (Humphrey, Loft \& Woods, 2009).

Ocorre que o resultado de uma internacionalização dos padrões de educação voltados para o ensino contábil pode gerar diversos impactos na formação e atuação dos contadores nos mais diversos territórios, como alterações nas diretrizes curriculares, melhorias nas habilidades interpessoais, e ainda, mudanças nos requisitos de entrada nos cursos, de experiência prática e desenvolvimento profissional contínuo.

Neste sentido, no contexto do ambiente da educação contábil brasileira, e considerando o que propõe o International Accounting Education Standards Board, o estudo apresenta a seguinte questão de pesquisa: Como é a percepção dos profissionais, pesquisadores e professores de contabilidade quanto às possíveis influências das Normas Internacionais de Educação Contábil? Desta forma, temse como objetivo de pesquisa investigar, sob a ótica dos profissionais, pesquisadores e professores de contabilidade, como as Normas Internacionais de Educação Contábil propostas pelo IAESB podem influenciar o ambiente nacional de educação contábil.

Para tanto, considera-se como ambiente nacional de educação contábil para a pesquisa em questão, todos os aspectos relacionados ao ensino, formação e atuação dos profissionais contábeis, desde os requisitos de entrada nos cursos, a formação inicial do aluno, a prática contábil, sua entrada no mercado, a educação continuada e demais aspectos sociais, políticos, econômicos e profissionais que tenham inter-relação com o ensino da contabilidade no Brasil.

A realização da presente pesquisa justifica-se devido às suas contribuições em três perspectivas distintas: teórica, prática e social. Sob o ponto de vista teórico, pesquisas em torno dos impactos das Normas Internacionais de Educação Contábil propostas pelo IAESB caracterizam-se como importantes pontos de investigação científica, visto que a qualidade do ensino neste âmbito possui impacto direto sobre a qualidade da informação contábil gerada pelos indivíduos (Crawford, Hellliar, Monk \& Veneziani, 2014).

Como contribuição prática, pesquisas neste âmbito podem ajudar a resolver questões voltadas à formação do contador, como o desenvolvimento de habilidades interpessoais, intelectuais e de comunicação, adequando-a às exigências da profissão e sua capacitação profissional. A busca por uma convergência contábil em âmbito mundial passa por uma discussão mais profunda sobre harmonização dos padrões de ensino em cursos de Ciências Contábeis. Um contador advindo de uma 
formação padronizada internacionalmente, deve estar capacitado para atuar em qualquer lugar do mundo (Crawford et al., 2014).

Quanto à contribuição social do estudo, a pesquisa colabora para informar todos os envolvidos e interessados no processo de ensino-aprendizagem em âmbito contábil (professores, acadêmicos, gestores de instituições de ensino), a respeito das Normas Internacionais de Educação Contábil que estão sendo difundidos em nível global pelo IAESB.

Destaca-se ainda a originalidade da pesquisa, visto que não foram encontradas publicações na América Latina que envolvam o escopo das IES, assim como os aspectos voltados ao IAESB, corroborando com os achados de Sugahara e Wilson (2013). As bases de dados pesquisadas são mencionadas no tópico pertinente aos estudos relacionados.

\section{FUNDAMENTAÇÃO TEÓRICA}

\subsection{International Accounting Education Standard Board}

O International Accounting Education Standards Board (IAESB) é um órgão normatizador independente, que serve ao interesse público por meio do fortalecimento da profissão contábil em todo o mundo, através do desenvolvimento e melhoria da educação. A visão do IAESB é trabalhar em prol do interesse público, desenvolvendo Padrões de Ensino em Contabilidade e orientações, para que sejam adotados e aplicados internacionalmente pelos órgãos membros da IFAC, assim como outras entidades interessadas na educação contábil, tais como universidades, instituições de ensino, entidades patronais, órgãos reguladores, autoridades governamentais, contadores e acadêmicos (IAESB, 2013a; 2014a).

Desta forma, todo processo de normatização desempenhado pelo IAESB é supervisionado pelo Public Interest Oversight Board (PIOB), um órgão global de supervisão independente, que visa fiscalizar as atividades e a qualidade das normas internacionais formulados por boards do IFAC. Com isto, busca garantir a transparência e integridade em todos os processos envolvendo a profissão contábil e de auditoria, primando sempre pelo interesse público e a melhoria da qualidade do reporte financeiro internacional (IAESB, 2013a; 2014a). Apesar de ser um board totalmente independente, o IAESB recebe apoio financeiro, operacional e administrativo do IFAC, de modo que são colocados à disposição do IAESB voluntários qualificados e concentrados exclusivamente nas atividades de definição de padrões exercidas pelo IAESB (Crawford et al. 2014; IAESB, 2014a).

A composição do IAESB é formada por um presidente, um vice-presidente e mais dezesseis membros voluntários de todo mundo, totalizando dezoito membros, entre eles: acadêmicos, profissionais de contabilidade do setor público, do setor privado e outros indivíduos com interesse no trabalho desenvolvido pelo IAESB, apesar de não terem vínculo direto com a contabilidade. Dos dezoito membros, nove são indivíduos com algum tipo de vínculo profissional na área contábil e nove não possuem vínculos empregatícios com empresas de contabilidade ou auditoria. Dos nove membros sem vínculos, no mínimo três são ligados a órgãos públicos, desta forma, espera-se que estes indivíduos reflitam à respeito dos processos do IAESB focados em decisões voltadas ao interesse público. Todos os membros do conselho são obrigados a assinar uma declaração anual de que irão pautar suas atitudes com integridade, visando sempre o interesse público no exercício de suas funções como membros do IAESB. A indicação dos membros ocorre por nomeação do conselho do IFAC, com base em recomendações e com a aprovação do PIOB (IAESB, 2014a).

O desenvolvimento dos pronunciamentos do IAESB segue um rigoroso processo. Esboços de propostas de pronunciamentos são publicados no website da entidade com acesso a todos os interessados, os comentários são analisados e os pronunciamentos finais são acompanhados por uma série de embasamentos e argumentações. O PIOB supervisiona o trabalho do IAESB e de seu conselho 
consultor, o IAESB's Consultative Advisory Group (CAG), para garantir que as atividades desenvolvidas sigam os devidos processos regulamentados e sejam compatíveis com o interesse público. O CAG por sua vez, é um conselho independente, que compreende stakeholders com interesse na educação internacional de contabilidade. Os membros deste conselho consultivo fornecem consultoria estratégica e técnica ao IAESB, no que tange o interesse público voltado aos padrões educacionais propostos, podendo argumentar e ponderar à respeito de suas deliberações (Crawford et al. 2014; IAESB, 2013a).

O IAESB é dedicado a operar da maneira mais transparente possível e suas reuniões, atas, agenda e documentos de apoio são abertos ao público e disponibilizados em seu website. Além disso, o portal online inclui projetos, consulta a documentos, minutas de trabalho e todos os comentários feitos por órgãos reguladores, empresas, pesquisadores, professores, conselheiros e todos aqueles interessados (IAESB, 2013a, 2013b).

No que tange a suas atribuições, o IAESB desenvolve normas e orientações sobre a aprendizagem e desenvolvimento necessários para ampliar e manter a competência sobre a carreira de um contador profissional. Atua ainda como catalisador para reunir as nações e ajudar no avanço dos programas de educação voltados à contabilidade em todo o mundo, em especial, quando estes programas são voltados ao interesse público e desenvolvimento econômico destes países (Karreman \& NEEDLES, 2013; IAESB, 2013a). Sendo assim, os principais objetivos do framework proposto pelo IAESB (2014a) podem ser definidos como:

a) Criação de uma série de padrões de alta qualidade e outras publicações que reflitam as boas práticas na educação, no desenvolvimento e avaliação dos profissionais contábeis;

b) Promover a adoção e implementação das Normas Internacionais de Educação;

c) Desenvolver benchmarks de educação para medir a implementação das Normas Internacionais de Educação;

d) Avançar no debate internacional sobre questões emergentes relativas à educação, desenvolvimento e avaliação dos profissionais contábeis.

O IAESB desenvolve e emite publicações sobre educação, formação e treinamento de profissionais contábeis, sendo elas:

Tabela 1 - Publicações emitidas pelo IAESB

\begin{tabular}{|c|l|l|}
\hline Sigla & \multicolumn{1}{|c|}{ Definição } & \multicolumn{1}{c|}{ Escopo } \\
\hline IES & $\begin{array}{l}\text { International } \\
\text { Standard Educa- } \\
\text { tion }\end{array}$ & $\begin{array}{l}\text { Normas Internacionais de Educação Contábil que abordam os princípios de } \\
\text { aprendizagem e desenvolvimento para profissionais de contabilidade. Elas devem ser } \\
\text { incorporadas aos requisitos educacionais de órgãos membros da IFAC. }\end{array}$ \\
\hline IEPS & $\begin{array}{l}\text { International } \\
\text { Education Prac- } \\
\text { tice Statements }\end{array}$ & $\begin{array}{l}\text { Declarações de Práticas de Educação Internacional que auxiliam na implementação } \\
\text { de boas práticas na aprendizagem e desenvolvimento de profissionais de contabili- } \\
\text { dade. As IEPS podem ser compostas de interpretações mais aprofundadas a respeito } \\
\text { de uma IES específica. }\end{array}$ \\
\hline IEIP & $\begin{array}{l}\text { International } \\
\text { Education Infor- } \\
\text { mation Papers }\end{array}$ & $\begin{array}{l}\text { Documentos Informacionais de Educação Internacional que fazem avaliações críti- } \\
\text { cas sobre questões emergentes de aprendizagem. Os objetivos das IEIP são promo- } \\
\text { ver o debate sobre estas questões e incentivar comentários e feedbacks das partes inte- } \\
\text { ressadas, fazendo com que tal interação possa angariar informações úteis para con- } \\
\text { fecção de futuras IES e IEPS. }\end{array}$ \\
\hline ASM & $\begin{array}{l}\text { Additional Sup- } \\
\text { port Material }\end{array}$ & $\begin{array}{l}\text { Os Materiais de Suporte Adicional podem ser caracterizados como kits de treina- } \\
\text { mento e materiais orientativos. }\end{array}$ \\
\hline
\end{tabular}

Fonte: Elaborado pelos autores com base em IAESB (2014a).

Conforme observa-se na Tabela 1, o IEASB emite basicamente quatro tipos de publicações, cada qual com suas particularidades e escopo distintos (IAESB, 2014a). Dentre estas, destacam-se as International Education Standards, sobre as quais passa-se a discorrer. 


\subsection{International Education Standards}

Por meio de suas atividades, o IAESB aprimora a educação voltada à contabilidade através do desenvolvimento e execução das Normas Internacionais de Educação Contábil, as International Education Standards (IES). Estas normas ampliam a competência da profissão contábil em nível mundial, contribuindo para o fortalecimento da confiança pública na contabilidade (Karreman \& Needles, 2013; IAESB, 2013a).

As IES auxiliam as instituições de ensino, órgãos reguladores, professores, estudantes, empregadores e a todos aqueles interessados, devido à sua prescrição de princípios para a aprendizagem e desenvolvimento de profissionais contábeis. Um padrão educacional internacional fornece aos órgãos membros da IFAC, e outras partes interessadas no ensino de contabilidade, um ponto de referência comum. Além disso, padrões aceitos globalmente podem minimizar as diferenças entre os países e jurisdições, reduzindo, desta forma, as divergências nos requisitos para se qualificar e trabalhar como um contador ao longo do globo (Sugahara \& Wilson, 2013; IAESB, 2013a).

Um dos benefícios da adequação ao framework proposto pelo IAESB, por meio das IES, é a possibilidade da realização de benchmarks internacionais, onde as entidades membros da IFAC poderão medir as lacunas reais entre o desenvolvimento na educação contábil em cada localidade. No Brasil, o Conselho Federal de Contabilidade (CFC) e o Instituto de Auditores Independentes do Brasil (IBRACON) são órgãos associados à IFAC. Desta forma, estão sujeitos às normatizações editadas pelo IAESB, o que implica no compromisso de empenhar-se no desenvolvimento da convergência aos padrões estabelecidos (IFAC, 2012; Karreman \& Needles, 2013).

As IES são divididas em dois estágios, Initial Professional Development (IPD) e o Continuing Professional Development (CPD, sendo oito normas já editadas: 
Tabela 2 - International Education Standards editadas pelo IAESB Initial Professional Development (IPD) - Desenvolvimento Profissional Inicial

\begin{tabular}{|c|c|c|}
\hline \multicolumn{3}{|c|}{ Initial Professional Development (IPD) - Desenvolvimento Profissional Inicial } \\
\hline IES 1 & $\begin{array}{c}\text { Requisitos de entrada em Programas de Educação Profissional em Conta- } \\
\text { bilidade }\end{array}$ & Vigência: 01/07/2014 \\
\hline Escopo & \multicolumn{2}{|c|}{$\begin{array}{l}\text { Estabelece princípios a serem utilizados na definição e comunicação dos requisitos educacionais para o } \\
\text { ingresso em programas de educação profissional em contabilidade. }\end{array}$} \\
\hline IES 2 & Competência Técnica & Vigência: 01/07/2015 \\
\hline Escopo & \multicolumn{2}{|c|}{$\begin{array}{l}\text { Estabelece os resultados da aprendizagem de competências técnicas que aspirantes a profissionais de } \\
\text { contabilidade devem demonstrar até o final do período de Desenvolvimento Profissional Inicial. A com- } \\
\text { petência técnica é a capacidade de aplicar o conhecimento profissional para desempenhar atividades com } \\
\text { um padrão definido. }\end{array}$} \\
\hline IES 3 & Habilidades Profissionais & Vigência: 01/07/2015 \\
\hline Escopo & \multicolumn{2}{|c|}{$\begin{array}{l}\text { Estabelece os resultados da aprendizagem de competências profissionais que aspirantes a profissionais } \\
\text { de contabilidade devem demonstrar até o final do período de Desenvolvimento Profissional Inicial. Ha- } \\
\text { bilidades profissionais são: a) intelectual; b) interpessoal e comunicação; c) pessoal; d) capacidade de or- } \\
\text { ganização de um profissional contábil integra-se com técnicos valores de competência e profissional, ética } \\
\text { e atitudes para demonstrar competência profissional. }\end{array}$} \\
\hline IES 4 & Valores Profissionais, Ética e Atitudes & Vigência: 01/07/2015 \\
\hline Escopo & \multicolumn{2}{|c|}{$\begin{array}{l}\text { Estabelece os resultados da aprendizagem referentes a valores profissionais, ética e atitudes que aspiran- } \\
\text { tes a profissionais de contabilidade devem demonstrar até o final do período de Desenvolvimento Pro- } \\
\text { fissional Inicial. }\end{array}$} \\
\hline IES 5 & Experiência Prática & Vigência: 01/07/2015 \\
\hline Escopo & \multicolumn{2}{|c|}{$\begin{array}{l}\text { Estabelece a experiência prática necessária que aspirantes a profissionais de contabilidade devem de- } \\
\text { monstrar até o final do período de Desenvolvimento Profissional Inicial. }\end{array}$} \\
\hline IES 6 & Avaliação da Competência Profissional & Vigência: 01/07/2015 \\
\hline Escopo & \multicolumn{2}{|c|}{$\begin{array}{l}\text { Estabelece requisitos para avaliação da competência profissionais que aspirantes a profissionais de con- } \\
\text { tabilidade devem demonstrar até o final do período de Desenvolvimento Profissional Inicial. }\end{array}$} \\
\hline \multicolumn{3}{|c|}{ Continuing Professional Development (CPD) - Desenvolvimento Profissional Contínuo } \\
\hline IES 7 & Desenvolvimento Profissional Contínuo & Vigência: 01/01/2014 \\
\hline Escopo & $\begin{array}{l}\text { Estabelece o desenvolvimento profissional contínuo necessário para que co } \\
\text { volvam e mantenham sua competência profissional. }\end{array}$ & profissionais desen- \\
\hline IES 8 & Requisitos de competência para Profissionais de Auditoria & Vigência: 01/07/2008 \\
\hline Escopo & \multicolumn{2}{|c|}{$\begin{array}{l}\text { Estabelece requisitos de competência para profissionais de auditoria, incluindo aqueles que trabalham } \\
\text { em ambientes e indústrias específicas. Especifica políticas e procedimentos que os aspirantes a profissio- } \\
\text { nais de auditoria devem satisfazer, antes de assumirem tais cargos. }\end{array}$} \\
\hline
\end{tabular}

Fonte: Elaborado pelos autores com base em IAESB (2014a).

O IPD é a primeira etapa de um contínuo aprendizado, na qual contemplam-se aspectos voltados à educação geral, educação profissional, experiência prática e avaliações de desempenho. Neste período, a aprendizagem deve ir além do conhecimento de princípios, normas e conceitos, incluindo a capacidade de integrar o conhecimento e competências profissionais a valores e princípios éticos.

Cada órgão membro da IFAC pode definir a duração mais apropriada entre o fim do IPD e o ponto de qualificação ou licença profissional (IAESB, 2014a; 2014b). Já o CPD ocorre após o término do IPD, onde busca-se manter o desenvolvimento profissional adquirido e possibilitar o bom desempenho de suas funções profissionais. O CPD caracteriza-se nos moldes de educação continuada, e pretende promover o desenvolvimento profissional ao longo do tempo (IAESB, 2014a; 2014b).

\subsection{Estudos Relacionados}

Neste tópico apresentam-se pesquisas relacionadas às Normas Internacionais de Educação Contábil e ao IAESB. Realizou-se um levantamento nas bases de dados Scopus, Spell, Science Direct, Jstor, Portal de Periódicos CAPES e Google Scholar, buscando-se por artigos contendo ao menos uma das expressões "IAESB", "International Education Standards Board", "IES", "International Educa- 
tion Standards", no título, resumo ou palavras-chave do estudo. Dentre os artigos encontrados, desconsiderou-se aqueles que continham as expressões de maneira aleatória e não tratavam do assunto como temática central do estudo.

Após a análise dos artigos, foram incluídas pesquisas que não foram localizadas na busca realizada nas bases de dados, no entanto, eram constantemente referenciadas pelas demais pesquisas encontradas, caracterizando-se como suma importância para este estudo. A seguir, observa-se na Tabela 3 um breve panorama dos estudos evidenciados.

Tabela 3 - Estudos relacionados

\begin{tabular}{|c|c|c|}
\hline \\
\hline Autores & Título & Escopo da pesquisa \\
\hline $\begin{array}{l}\text { Karreman } \\
(2002)\end{array}$ & $\begin{array}{l}\text { Impact of Globalisation on Accountancy } \\
\text { Education }\end{array}$ & $\begin{array}{l}\text { Análise do impacto da globalização sobre a educação contá- } \\
\text { bil em } 25 \text { países. }\end{array}$ \\
\hline $\begin{array}{l}\text { Phelps e Kar- } \\
\text { reman (2005) }\end{array}$ & $\begin{array}{l}\text { Report on the Results of the Global Ac- } \\
\text { counting Education Benchmarking Pilot } \\
\text { Project }\end{array}$ & $\begin{array}{l}\text { Realização de um benchmarking global a fim de medir como } \\
\text { os órgãos de classe contábil nos países pesquisados, prepa- } \\
\text { ram seus membros com relação à capacidade e competência } \\
\text { profissional exigidos pelas IES. }\end{array}$ \\
\hline $\begin{array}{l}\text { Peek et al. } \\
(2007)\end{array}$ & $\begin{array}{l}\text { NAFTA Professional Mutual Recogni- } \\
\text { tion Agreements: Comparative Analysis } \\
\text { of Accountancy Certification and Licen- } \\
\text { sure }\end{array}$ & $\begin{array}{l}\text { Análise comparativa dos acordos de certificação e licencia- } \\
\text { mento de programas de contabilidade nos EUA, México e } \\
\text { Canadá, buscando parâmetros para que professores possam } \\
\text { preparar da melhor maneira possível os estudantes para } \\
\text { oportunidades de carreira internacional por meio do North } \\
\text { American Free Trade Agreement. }\end{array}$ \\
\hline $\begin{array}{l}\text { Stainbank e } \\
\text { Ramatho } \\
(2007)\end{array}$ & $\begin{array}{l}\text { Professional accountancy education in } \\
\text { selected ECSAFA countries: a compara- } \\
\text { tive study }\end{array}$ & $\begin{array}{l}\text { Análise comparativa da educação em programas de contabi- } \\
\text { lidade em } 25 \text { países. A pesquisa amplia o estudo de Karre- } \\
\text { man (2002) realizando um benchmarking entre os programas } \\
\text { de educação contábil. }\end{array}$ \\
\hline $\begin{array}{l}\text { Crawford et } \\
\text { al. }(2010)\end{array}$ & $\begin{array}{l}\text { IES Compliance and the knowledge, } \\
\text { skills and values of IES 2, } 3 \text { and } 4 .\end{array}$ & $\begin{array}{l}\text { Análise do compliance das IES 2, } 3 \text { e } 4 \text { frente a } 21 \text { órgãos } \\
\text { membros da IFAC em } 12 \text { países selecionados. }\end{array}$ \\
\hline $\begin{array}{l}\text { Sugahara e } \\
\text { Boland (2011) }\end{array}$ & $\begin{array}{l}\text { Effects of exposure to the IES on per- } \\
\text { ceived importance of the global harmoni- } \\
\text { zation of accounting education among } \\
\text { Japanese accounting academics }\end{array}$ & $\begin{array}{l}\text { Análise do grau de conhecimento das IES e a percepção da } \\
\text { importância da harmonização internacional da educação } \\
\text { contábil de professores de contabilidade japoneses. }\end{array}$ \\
\hline $\begin{array}{l}\text { Sugahara e } \\
\text { Wilson (2013) }\end{array}$ & $\begin{array}{l}\text { Discourse Surrounding the IES for Pro- } \\
\text { fessional Accountants (IES): A Content } \\
\text { Analysis Approach }\end{array}$ & $\begin{array}{l}\text { Análise de conteúdo em } 110 \text { artigos publicados em inglês } \\
\text { durante o período de } 2003 \text { a 2011, objetivando analisar a } \\
\text { opinião dos pesquisadores quanto as IES }\end{array}$ \\
\hline $\begin{array}{l}\text { Karreman e } \\
\text { Needles } \\
(2013)\end{array}$ & $\begin{array}{l}\text { Global Accountancy Education Recog- } \\
\text { nition Study } 2012\end{array}$ & $\begin{array}{l}\text { Comparação sistemática dos requisitos de qualificação pro- } \\
\text { fissional para contadores em } 16 \text { países. }\end{array}$ \\
\hline Helliar (2013) & $\begin{array}{l}\text { The Global Challenge for Accounting } \\
\text { Education }\end{array}$ & $\begin{array}{l}\text { Utiliza a perspectiva da teoria institucional para debater a } \\
\text { respeito da contabilidade; teorias de ensino e aprendiza- } \\
\text { gem; e educação contábil. Tece reflexões idealizando um } \\
\text { planejamento para educação contábil no futuro. }\end{array}$ \\
\hline $\begin{array}{l}\text { Crawford et } \\
\text { al. (2014) }\end{array}$ & $\begin{array}{l}\text { IAESB: Organisational legitimacy } \\
\text { within the field of professionalaccount- } \\
\text { ancy education }\end{array}$ & $\begin{array}{l}\text { Avaliação da legitimidade do IAESB em instituir as IES } \\
\text { frente as diferentes jurisdições mundiais. }\end{array}$ \\
\hline $\begin{array}{l}\text { Watty et al. } \\
(2014)\end{array}$ & $\begin{array}{l}\text { Towards a Global Model of Accounting } \\
\text { Education }\end{array}$ & $\begin{array}{l}\text { Análise dos sistemas de educação contábil em três países, } \\
\text { Austrália, Japão e Sri Lanka, quanto a sua adequação as IES. }\end{array}$ \\
\hline
\end{tabular}

Fonte: Elaborado pelos autores.

Destaca-se que não foram encontradas pesquisas publicadas na América Latina contendo as referidas expressões, assim como os achados de Sugahara e Boland (2013). 


\section{PROCEDIMENTOS METODOLÓGICOS}

O delineamento da pesquisa refere-se à identificação do conjunto metodológico mais apropriado para realização do estudo proposto. Quanto à abordagem do problema, a pesquisa é classificada como qualitativa, e com relação ao seu objetivo, classifica-se como descritiva. Quanto aos procedimentos de pesquisa adotados, caracteriza-se como pesquisa documental, de levantamento e de análise descritiva.

Inicialmente realizou-se uma minuciosa análise documental do Handbook of International Education Pronouncements do IAESB (2014a), que contempla todas as 8 normas internacionais voltadas para o ensino contábil, utilizando-se como suporte outros documentos orientativos que tratam das IES, como IAESB (2006), IAESB (2012), IFAC (2012), IAESB (2013a), IAESB (2013b) e IAESB (2014b). Desta forma, como resultado, obteve-se oito tópicos na sessão voltada aos resultados da pesquisa, cada uma delas trazendo um panorama à respeito de cada norma específica.

No que tange ao levantamento de dados, aplicaram-se questionários com perguntas abertas e/ou entrevistas estruturadas com base no questionário formulado, ficando a critério dos respondentes a opção do instrumento de resposta.

Para delimitar uma amostra de pesquisados que contemplasse os diversos atores do contexto do universo contábil, foram selecionados por acessibilidade, representantes de quatro âmbitos da contabilidade, conforme observa-se na Figura 1:

Figura 1 - Diferentes perspectivas dos entrevistados frente à temática proposta

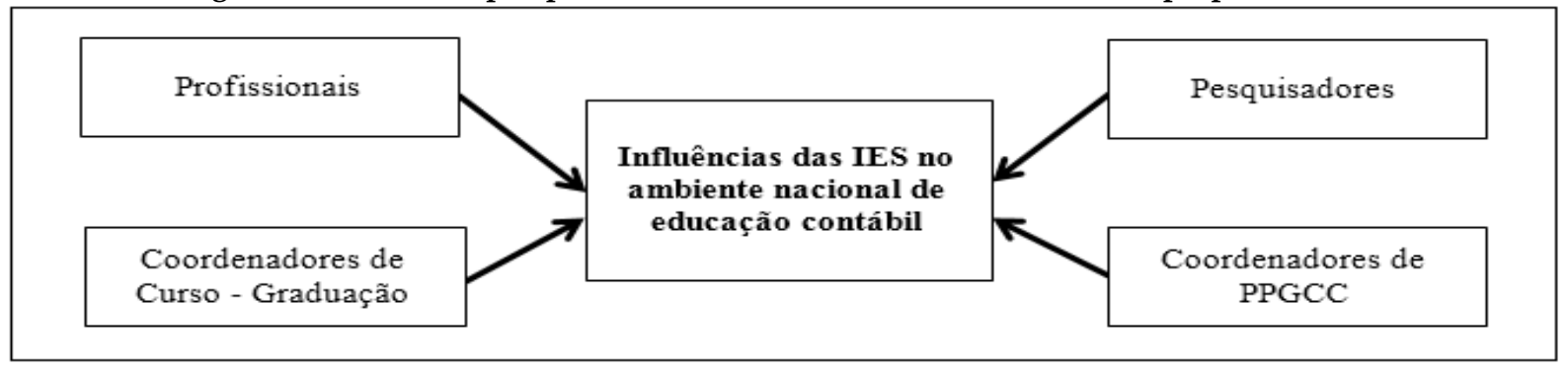

Fonte: Elaborado pelos autores.

Após a coleta dos dados, empregou-se a técnica de triangulação de dados entre a teoria, análise documental e análise das entrevistas e questionários aplicados, com intuito de se obter uma descrição robusta e detalhada dos fenômenos analisados. Ao contrastar evidências coletadas por diversas técnicas, busca-se uma maior confiabilidade e credibilidade das informações e resultados evidenciados (Olsen, 2004; Flick, 2009).

A triangulação almeja observar um mesmo problema de pesquisa, por meio de mais de uma fonte dados, desta forma, informações advindas de diferentes perspectivas podem ser utilizadas para corroborar com o problema de pesquisa, limitando os vieses pessoais e metodológicos do pesquisador (Maxwell, 2004; Flick, 2009).

A pesquisa realizada apresenta limitações que merecem ser destacadas. Uma das restrições está relacionada ao universo pesquisado, desta forma, os resultados obtidos não podem ser generalizados, sendo estes resultantes da perspectiva dos profissionais, pesquisadores e professores envolvidos na pesquisa. Todavia, ressalta-se que foram entrevistados indivíduos de diversas localidades do Brasil, e pela relevância dos profissionais entrevistados em nível nacional e estadual, pesquisadores doutores com reconhecida experiência e atuação na área de educação contábil no Brasil, professores coordenadores de cursos de graduação de naturezas distintas e professores coordenadores de PPGCC, têm-se os achados como significantes inferências e contribuições para o avanço da literatura relacionada, aprofundando-se as concepções a respeito do fenômeno investigado. 
Ressalta-se que esse estudo não pretende esgotar toda discussão inerente a temática da pesquisa, mas sim contribuir com os estudos já realizados, e servir como insights para pesquisas futuras.

\section{ANÁLISE E INTERPRETAÇÃO DOS RESULTADOS}

\subsection{Análise das International Education Standard}

\subsubsection{International Education Standard 1}

A IES 1 trata dos Requisitos de entrada em Programas de Educação Profissional em Contabilidade e estabelece os princípios a serem utilizados na definição e comunicação aos órgãos membros da IFAC sobre os requisitos educacionais para o ingresso em programas de educação contábil. A despeito das políticas curriculares nacionais originarem-se no âmbito do Conselho Nacional de Educação (CNE), esta IES pode auxiliar as entidades regulamentadoras que credenciam e apoiam programas de educação contábil (IAESB, 2014a).

De acordo com esta norma, os órgãos membros da IFAC devem especificar requisitos de entrada em programas de educação contábil, permitindo que somente aqueles com chance razoável de concluir com sucesso os programas ofertados, ingressem nestes, embora tais requisitos não devam representar barreiras excessivas. Os requisitos devem ser estabelecidos de maneira pertinente e postos à disposição do público para auxiliar os indivíduos a avaliarem suas próprias chances de concluir tais programas.

Os órgãos membros da IFAC podem coletar diversas informações, de forma transparente, em uma base de dados contínua, que pode ser analisada e utilizada para fornecer subsídios aos interessados em ingressar em uma carreira como profissional contábil, tais como a variação de pontos dos candidatos ingressantes, taxas relativas aos testes para qualificação, custos para conclusão de um programa de educação contábil e expectativas de competências e conhecimentos a serem adquiridos após uma conclusão bem sucedida de programas de educação contábil. O IAESB reconhece que os requisitos de entrada podem variar de acordo com as diferenças existentes nas várias jurisdições, como por diferenças na legislação, testes de entrada, experiência mínima e outros fatores.

\subsubsection{International Education Standard 2}

A norma IES 2, intitulada Competências Técnicas, trata dos resultados da aprendizagem que os alunos devem demonstrar até o final do IPD. A competência técnica é a capacidade de executar uma função dentro de um padrão estabelecido, no entanto, este conceito vai além de princípios, normas, conceitos e procedimentos, ele diz respeito à integração de três fatores: competência técnica, competência profissional e valores profissionais (IAESB, 2014a).

A competência técnica por si só, refere-se a áreas de competência específica, como contabilidade, tributação e relatórios financeiros. A competência profissional, por sua vez, está atrelada a habilidades intelectuais e organizacionais do indivíduo. Já os valores profissionais, referem-se a atitudes e princípios éticos, assim como o ceticismo e julgamento profissional.

Estabelecer a competência técnica que aspirantes a profissionais contábeis precisam desenvolver e demonstrar até o final do IPD auxilia na consecução de diversos propósitos, como a proteção do interesse público, melhora na qualidade dos profissionais contábeis e o aumento da credibilidade da profissão. É responsabilidade dos órgãos membros da IFAC assegurar que os estudantes alcancem. Até o período final do IPD, diversos resultados de aprendizagem voltados a áreas de competência como Contabilidade Financeira, Contabilidade Gerencial, Auditoria, Finanças, Economia, Legislação, Tecnologia da Informação, Gestão de Negócios conforme, dentre outras conforme detalha o IAESB (2014a, p. 237).

Estes resultados de aprendizagem são a base para habilitar profissionais contábeis, independentemente da atuação ou especialização futuramente pretendida. A partir desta base, os indivíduos 
devem estar aptos a desenvolver especialidades em funções mais específicas como auditoria ou tributação.

\subsubsection{International Education Standard 3}

Nos mesmos moldes da IES anterior, a IES 3, Habilidade Profissionais, estabelece os resultados de aprendizagem que os estudantes devem demonstrar até o final do período de IPD, no que se refere as seguintes habilidades:

Tabela 4 - Habilidades Profissionais estabelecidas pela IES 3

Intelectual: capacidade de um contador resolver problemas, tomar decisões e exercer julgamento profissional.

Interpessoal e de comunicação: capacidade de um contador de trabalhar e interagir eficazmente com outros indiví-

duos.

Pessoal: relacionar-se atitudes e comportamentos pertinentes de contador profissional.

Organizacional: refere-se à capacidade de um contador de trabalhar de maneira eficaz, com ou dentro de uma orga-

nização, para obter os melhores resultados com as pessoas e recursos disponíveis.

Fonte: Elaborado pelos autores com base em IAESB (2014a).

Além das habilidades destacadas na Tabela 4, os resultados de aprendizagem devem assegurar ainda a integração destas com os demais aspectos de Competência Técnica (IES 2) e Valores Profissionais, Ética e Atitudes (IES 4). As Habilidades Profissionais estabelecidas pelas IES 3 foram desenvolvidas com o intuito de fornecer uma perspectiva mais ampla, e auxiliar os futuros profissionais contábeis a se comunicar de forma eficaz, desenvolver o raciocínio lógico e análises críticas mediantes problemas do cotidiano.

Assim como ocorre com as Competências Técnicas (IES 2), as concepções das quatro áreas de competência relativas às Habilidades Profissionais podem variar de acordo com peculiaridades de cada programa de educação contábil. A consecução de alguns resultados esperados pode ser atingida dentro de uma ou mais disciplinas diferentes, além disso, há diversas maneiras de se descrever e classificar tais habilidades, assim como seus níveis de proficiência (IAESB, 2014a; 2014b).

\subsubsection{International Education Standard 4}

A IES 4 aborda as questões relativas aos Valores Profissionais, Ética e Atitudes, voltando-se ao comportamento profissional e às características que identificam os contadores como membros de uma profissão. Estes aspectos incluem os princípios éticos geralmente associados e considerados como essenciais na conduta dos profissionais contábeis durante o desempenho de suas atividades (IAESB, 2014a).

As exigências éticas elencadas por esta norma seguem os preceitos do International Ethics Standard Board for Accountants (IESBA), um órgão normatizador independente que serve ao interesse público através da criação de padrões éticos internacionais para contadores e auditores, que foram compilados no Code of Ethics for Professional Accountants. Considera-se a IES 4, portanto, de grande relevância para educação profissional de contabilidade, sendo definida por cinco princípios fundamentais da ética profissional: Integridade, Objetividade, Competência e Diligência Profissional, Confidencialidade e Comportamento Profissional. Estes princípios podem ser melhor elucidados em IAESB (2014a) e IESBA (2014).

Os órgãos membros da IFAC devem prescrever nos programas de ensino contábil, diversos resultados de aprendizagem (ver IAESB, 2014a, p. 260) referentes aos Valores Profissionais, Ética e Atitudes que devem ser atestados até o final do IPD pelos estudantes. As três áreas de competência inerentes aos resultados de aprendizagem esperados pela IES 4 são: Ceticismo e Julgamento Profissional, os Princípios Éticos e o Compromisso com o interesse público. 
O Ceticismo Profissional é uma atitude questionadora, onde o profissional mantém-se alerta para condições que possam indicar possíveis distorções, como erros e fraudes, em determinada avaliação crítica. O Julgamento Profissional refere-se à aplicação adequada dos conhecimentos, técnicas e experiências profissionais dentro de um contexto contábil e de auditoria, na tomada de decisão relacionada a ações que são apropriadas ou não em certas circunstâncias e situações profissionais. Os Princípios Éticos condizem basicamente com os cinco princípios fundamentais acima relatados pelo IESBA (2014). Por fim, o Compromisso com o interesse público refere-se à relação da ética profissional com a responsabilidade social, a boa governança e a responsabilidade de agir em direção ao interesse público, desta forma, as ações dos contadores não devem destinar-se a satisfazer exclusivamente as necessidades de seus clientes (IAESB, 2014a; IESBA; 2014).

Dentro de um programa de educação contábil, as características da IES 4 podem ser tratadas em uma disciplina específica, no entanto os estudantes devem ser instigados a aplicar tais valores cotidianamente, incentivandoa consideração de implicações éticas em contextos mais amplos (IAESB, 2014a). Além disso, deve-se considerar o uso de abordagens participativas durante o processo de ensino e aprendizagem que possibilitem o desenvolvimento dos valores profissionais, tais como: discussão de leituras selecionadas, análise de estudos de caso que envolvam dilemas éticos em situações de negócios, discussão à respeito dos regulamentos éticos e disciplinares, seminários, fóruns de discussão e a encenação pelos próprios alunos de situações que envolvam princípios éticos (IAESB, 2014a).

\subsubsection{International Education Standard 5}

A IES 5 refere-se à Experiência Prática que os estudantes devem comprovar e desenvolver durante o período IPD nos programas de educação contábil. O principal objetivo desta IES é fazer com que o graduando, após a conclusão do curso, possua a experiência prática necessária, estando apto e habilitado a desempenhar as funções de um contador profissional (IAESB, 2014a).

A experiência prática pode ser proporcionada em ambientes nos quais os estudantes possam tomar conhecimento da atmosfera em que os serviços são prestados, aumentar sua compreensão a respeitos do funcionamento dos negócios, relações de trabalho profissional e das particularidades de uma organização. A experiência prática suficiente, que deve ser atingida e comprovado ao final do IPD, caracteriza-se por uma junção dos conhecimentos adquiridos e aplicação destes em situações e contextos reais. A amplitude da experiência pode ser afetada por diversos fatores, como o nível de proficiência requerido, as exigências legais, variedade e complexidade das tarefas, bem como o nível de apoio e supervisão. Experiências sob supervisão apropriada propiciam, ainda, a oportunidade do desenvolvimento de responsabilidade, compromisso e conscientização por parte dos estudantes (IAESB, 2014a).

O estudo para obter-se as qualificações acadêmicas é útil para aquisição e demonstração de conhecimentos de contabilidade, no entanto, o estudo por si só não necessariamente mostra que o estudante possui a competência suficiente para desempenhar as funções de um profissional contábil. Para determinar o que constitui um equilíbrio adequado entre a educação contábil e a experiência prática, os órgãos membros da IFAC podem considerar fatores como períodos de estágios e experiência profissional, que podem ser realizados durante ao após o término dos programas.

Pode-se estabelecer qual tipo de abordagem será utilizada para medir a experiência prática, como a abordagem baseada em outputs/resultados, abordagem baseada em inputs, ou ainda, optar por uma combinação destas abordagens conforme detalhado em IAESB (2014a, p. 279). Independentemente da abordagem utilizada, há uma expectativa de que um indivíduo que esteja habilitado para desempenhar suas funções no mercado, tenha obtido a experiência prática suficiente para tal, além disso, é de interesse público que tais expectativas se concretizem (IAESB, 2014a; 2014b). 


\subsubsection{International Education Standard 6}

A IES 6 estabelece os requisitos para Avaliação da Competência Profissional nos programas de educação contábil, assim, esta norma detalha as condições de avaliação voltadas às quatro normas anteriores: IES 2, IES 3, IES 4 e IES 5. Avaliar se os estudantes atingiram um nível adequado de competência profissional serve a vários propósitos: o interesse público é protegido, a credibilidade da profissão contábil é reforçada, e os órgãos membros da IFAC cumprem sua função fiscalizadora no intuito de garantir que indivíduos por eles credenciados tenham a competência esperada por seus empregadores e clientes (IAESB, 2014a, 2014b).

Para avaliar formalmente se a competência profissional foi alcançada, pode-se utilizar os resultados de uma ou mais avaliações que ocorrem durante o IPD. A configuração destas avaliações pode variar de acordo com as necessidades de cada órgão, sendo que exemplos de atividades de avaliação podem incluir: um único exame multidisciplinar conduzido até o final do IPD, uma série de exames que se concentrem em áreas específicas de competência profissional realizados durante todo o IPD, diversos exames e avaliações nos locais onde os estudantes desenvolvem suas experiências práticas, ou ainda, avaliações a critério dos órgãos membros que propiciem os resultados desejados.

Diversos formatos de avaliação podem ser utilizados, como provas escritas, provas orais, testes objetivos, testes auxiliados por computador, avaliações realizadas pelos empregadores no local de trabalho, e avaliação de relatórios de atividades práticas realizadas. Os tipos de avaliações selecionadas podem variar de acordo com fatores específicos de cada órgão membro da IFAC, como a localização geográfica, recursos educacionais disponíveis, número de estudantes sendo avaliados, e a disponibilidade de oportunidades para experiências práticas.

As avaliações aplicadas com os estudantes durante o IPD devem alcançar altos níveis de confiabilidade, validade, equidade, transparência e suficiência para cada atividade de avaliação individual. Cada um destes princípios é aprofundado em IAESB (2014a, p. 283).

\subsubsection{International Education Standard 7}

A IES 7 prevê o chamado Continuing Professional Development (CPD), que se refere ao desenvolvimento profissional contínuo, para que os contadores profissionais mantenham a capacitação necessária para fornecer serviços de alta qualidade para seus clientes, empregadores e outras partes interessadas, reforçando assim a confiança pública na contabilidade.

Embora seja de responsabilidade dos próprios contadores manterem o constante desenvolvimento de suas competências profissionais através da realização de atividades de CPD obrigatórias, a IES 7 é dirigida aos órgãos membros da IFAC, tendo em vista o seu papel de fomentar o compromisso com a aprendizagem ao longo da vida dos profissionais, facilitar o acesso a oportunidades e recursos aos contabilistas, e adotar as normas relativas a implementação, desenvolvimento e monitoramento do CPD.

Conforme descreve a norma IES 7, o CPD caracteriza-se como uma continuação do IPD, que por meio de atividades de educação continuada dá prosseguimento ao know-how adquirido no estágio inicial. Além disso, os profissionais contábeis, ao longo de suas carreiras, podem assumir novas funções específicas, que exigem novas competências, em tais casos, o CPD pode incluir muitos dos mesmos elementos já vistos no IPD, porém fundamentais para o exercício de funções que exigem uma maior amplitude de conhecimentos e habilidades.

Além da educação continuada, da experiência prática e de treinamentos, o CPD inclui ainda outras atividades de aprendizagem e desenvolvimento, tais como: coaching e mentoring; criação de redes de relacionamento (networking); observação, feedback e reflexão; e atividades de autoaprendi- 
zagem. Devido à complexidade dos negócios, os profissionais contábeis enfrentam crescentes expectativas no que se refere às suas atividades e competências, e essas pressões se aplicam a profissionais contábeis em todos os setores. Para o IAESB (2014a) o CPD é fundamental para que os contadores atendam a estas demandas e continuem desempenhando suas atividades com a competência necessária, no entanto, assumem que nem todos os profissionais que participarem de programas de CPD irão absorver de maneira completa seus benefícios, sendo os resultados provenientes do empenho e capacidade de aprendizagem de cada indivíduo.

Segundo a norma, os programas de CPD devem ser monitorados e avaliados pelos órgãos membros da IFAC, devendo estes comunicar regularmente a importância dos programas de CPD aos profissionais contábeis, promover a variedade de oportunidades disponíveis de programas e conscientizar os interessados de sua importância.

Alguns exemplos de abordagens que podem ser realizadas como parte de um programa são: cursos; seminários; treinamentos; participação em comissões técnicas; estudo formal relacionado com a atividade profissional; participação como palestrante em conferências; escrever artigos, papers ou livros de natureza técnica, profissional ou acadêmica; exames de suficiência técnica; prover ou receber suporte de coaching (IAESB, 2014a).

Assim, observa-se que diversas são as atividades passíveis de implementar-se em um programa de CPD, sendo que estas aplicam-se a todos os profissionais contábeis, independentemente do setor ou tamanho da organização em que exercem suas atividades. Os órgãos membros da IFAC devem estabelecer processos sistemáticos para verificar se os contadores atendem aos requisitos exigidos CPD, prevendo as devidas sanções em caso do não atendimento destes requisitos (IASEB, 2014a).

\subsection{Análise das IES frente às influências identificadas na perspectiva dos Profissionais, Pesqui- sadores e Professores de Contabilidade}

Conforme os achados de Karreman (2002), a Educação Contábil é influenciada tanto pela profissão, quanto pelas instituições de ensino superior dentro de cada uma das jurisdições. A regulamentação governamental e as diretrizes dos órgãos regionais definem padrões para a educação contábil superior, que podem diferir de país para país. O desenvolvimento educacional contábil ocorre em países e regiões que possuem grandes diferenças, sejam elas devido à cultura, sistema jurídico, educacional ou econômico.

Frente a este panorama, as IES caracterizam-se como elementos fundamentais para harmonização da educação contábil, em que cada jurisdição pode realizar seu próprio benchmark e adequarse às Normas Internacionais de Educação Contábil propostas pelo IAESB, na medida em que suas estruturas internas aproximam-se do framework padrão.

Percebe-se, tanto na análise documental, quanto na perspectiva dos participantes da pesquisa, que a antiga ênfase nos requisitos de conhecimento passa a flexibilizar-se, e assim garantir uma formação mais abrangente dos profissionais contábeis, aliando questões técnicas a habilidades interpessoais e valores éticos que são fundamentais para o desempenho da profissão, haja vista a sua dinamicidade e constantes mudanças no ambiente contábil.

No entanto, embora os achados de Sugahara e Wilson (2013) apontem que as IES vem sendo discutidas em diversos países, destaca-se a inexistência de estudos relacionados as IES na América Latina, um grande contraste com regiões como América do Norte, Europa e Oceania, onde concentram-se a maioria das publicações. Este fato este corrobora com a percepção dos pesquisadores, quando do contato com os participantes da pesquisa, tendo em vista que estes, muitas vezes, demonstraram não possuir familiaridade com os aspectos relacionados as IES ou o próprio IEASB. Estes achados vão ao encontro dos resultados de Sugahara e Boland (2011), Sugahara e Wilson (2013) 
e Helliar (2013), que encontraram evidências de que muitos professores de contabilidade não estão cientes da existência das IES.

Conforme observado na análise documental, as oito IES contemplam dois estágios de aprendizagem: o Desenvolvimento Profissional Inicial e o Desenvolvimento Profissional Contínuo, formando a seguinte estrutura conceitual:

Figura 2 - Estrutura conceitual das IES

\begin{tabular}{|l|}
\hline IES 1 - Requisitos de Entrada \\
\hline Desenvolvimento Profissional Inicial \\
\hline IES 2 - Competências Técnicas \\
\hline IES 3 - Habilidades Profissionais \\
\hline IES 4 - Valores Profissionais, Etica e Atitudes \\
\hline IES 5 - Experiência Prática \\
\hline IES 6 - Avaliação da Competência Profissional \\
\hline IES 7 - Desenvolvimento Profissional Contínuo \\
\hline IES 8 - Competência para Profissionais de Auditoria \\
\hline
\end{tabular}

Fonte: Elaborado pelos autores.

Cada uma das IES dispõe a respeito de aspectos educacionais específicos, em seus respectivos estágios de aprendizagem. Com relação aos Requisitos de Entrada (IES 1), enquanto os Profissionais e os Coordenadores PPGCC, de maneira geral, acreditam que esta norma não causará grandes influências no ambiente nacional de educação contábil, tendo em vista que, em suas percepções, este já contempla os requisitos estabelecidos pela norma, os Pesquisadores e Coordenadores de Curso consideram que os requisitos de entrada no Brasil não cumprem os preceitos da IES 1, apesar de não representarem barreiras excessivas de entrada aos indivíduos.

Os resultados de Crawford et al. (2014) estabelecem que há uma grande variedade nas exigências de entrada nos diversos países investigados em sua amostra. No Brasil, os requisitos de entrada parecem estar adequados à essência do que propõe a IES 1, no entanto, tendo em vista o processo de mercantilização do ensino e a grande demanda de vagas não preenchidas em cursos de graduação de Ciências Contábeis, conforme relatado pelos participantes da pesquisa, o "processo seletivo" acaba perdendo sua eficácia. Com uma oferta de vagas nos cursos de Ciências Contábeis superior ao número de alunos ingressantes, constata-se como improvável qualquer forma de seleção.

Já com relação as Competências Técnicas (IES 2), em linhas gerais, os quatro grupos (Profissionais, Pesquisadores, Coordenadores de Curso e Coordenadores PPGCC) demonstraram similaridade em suas respostas. Em suma, afirmam que o ensino contábil no Brasil é demasiadamente tecnicista e reestruturar este panorama é tarefa fundamental. Estas perspectivas corroboram com os resultados de Crawford et al. (2010), que afirmam haver uma ênfase demasiada em contabilidade financeira e aspectos técnicos nos programas de educação contábil dos 12 países analisados, e ainda Crawford et al. (2014) afirmam que a maioria dos órgãos membros da IFAC contemplam os requisitos da IES 2, com exceção os países da América Latina.

Quanto às Habilidade Profissionais (IES 3), novamente percebe-se similaridade entre as respostas observadas. De maneira geral, os participantes de todos os grupos afirmam que as instituições de ensino superior no Brasil não estão aptas a potencializar o desenvolvimento de atributos voltados a habilidades intelectuais, de comunicação e relacionamento interpessoal aos acadêmicos de maneira suficiente, conforme preconiza a IES 3, embora em certas instituições específicas isso possa ocorrer. 
Segundo os pesquisados, as principais influências da IES 3 no ambiente nacional de educação contábil seriam: a) implementação de métodos de ensino ativos, como PBL, debates, estudos de caso e clusters de aprendizado; b) reestruturação das diretrizes curriculares dos cursos, ensejando uma formação holística, multidisciplinar e possibilitando a experiência prática em contextos reais; c) readaptação dos docentes à nova realidade de ensino e aprendizagem.

Estes achados corroboram com o estudo de Crawford et al. (2010) e Helliar (2013) que afirmam não haver foco suficiente em conhecimentos voltados aos negócios, habilidades interpessoais e de comunicação nos países investigados. As universidades devem utilizar uma ampla gama de métodos de ensino, bem como atentar ao desenvolvimento de melhorias, e um estudo mais profundo das questões que permeiam uma formação contábil holística. Este resultado corrobora ainda os achados de Karreman (2002), que identificou nos países investigados que os ensinamentos oferecidos no campo do conhecimento organizacional e de negócios são desenvolvidos sem a profundidade suficiente.

Com relação aos Valores Profissionais, Ética e Atitudes (IES 4), percebe-se similaridade nas perspectivas dos participantes da pesquisa, embora existam divergências pontuais. Os Profissionais, de maneira geral, percebem que o contador se preocupa com o interesse público, embora existam exceções. Para os Pesquisadores, a questão ética não é muito difundida no meio profissional. Para os Coordenadores de Curso, os contadores estão mais focados em cumprir leis e normas, sem se preocupar tanto com aspectos sociais, enquanto para os Coordenadores PPGCC, espera-se que, de maneira geral, os contadores se preocupem com o interesse público, embora reconheçam que isso ocorra em poucos casos.

Acerca dos aspectos de ceticismo e julgamento profissional, todos os pesquisados consideram que estes não são tratados de maneira suficiente nas instituições de ensino superior. O padrão internacional poderia surtir boas influências no ambiente nacional de educação contábil, impulsionando os órgãos de classe, instituições de ensino e entidades governamentais a buscarem alternativas para ampliar o desenvolvimento destas particularidades (aspectos éticos, de valores e atitudes) na formação acadêmica e profissional dos contabilistas.

Além disso, adequar-se ao modelo proposto pela IES 4, na opinião dos pesquisados, poderia melhorar a imagem da classe contábil perante a opinião pública. Estes achados vão ao encontro de estudos como Karreman (2002) e Crawford et al. (2014), nos quais identificou-se que os aspectos éticos são desenvolvidos de maneira superficial na formação dos profissionais de contabilidade. Os autores afirmam que as instituições de ensino superior devem potencializar e aprofundar tais valores nos indivíduos.

No tocante a Experiência Prática (IES 5), as concepções dos pesquisados foram, em certos pontos similares, enquanto em outros, divergentes. Os Profissionais consideram que a experiência prática deveria ser realizada obrigatoriamente em contextos reais. Os Pesquisadores afirmam que o atual modelo de experiência prática desenvolvido no ambiente nacional de ensino contábil não é suficiente para atingir os preceitos delineados pela IES 5. A parceria com empresas idôneas para propiciar aos alunos experiências práticas no cotidiano empresarial contábil, com o devido acompanhamento e monitoria seriam boas alternativas.

Para os Coordenadores de Curso, a experiência prática deveria ser realizada em contextos reais, no entanto, deve-se atentar a casos específicos em que alunos já estão inseridos no mercado de trabalho. Por fim, os Coordenadores PPGCC possuem opiniões divergentes, enquanto alguns consideram que o atual modelo praticado no Brasil está a contento com os preceitos da IES 5, outros afirmam que o modelo brasileiro é precário e, desta forma, a experiência prática deveria ser obrigatoriamente desenvolvida em contextos reais.

No que se refere a hipotética adoção aos modelos existentes em outros países, onde a experiência prática deveria ser obrigatoriamente comprovada, antes da adesão dos indivíduos aos órgãos 
de classe, os Profissionais e Pesquisadores afirmam que estes modelos não devem ser aplicados, principalmente devido aos problemas sociais existentes no contexto brasileiro, como o desemprego e a dificuldade de inclusão do jovem no mercado de trabalho. Já no grupo de Coordenadores de Curso, existem opiniões bastante divergentes entre indivíduos que concordam e discordam da adoção deste modelo, enquanto o grupo de Coordenadores PPGCC, de maneira geral, apoia a medida. Ressalta-se com relação a IES 5, os achados do estudo de Crawford et al. (2014) que evidenciaram frente ao CFC no Brasil e ao IMCP no México, que estes órgãos de classe não exigem nenhum tipo de experiência prática prévia, formalizada e documentada, antes da adesão dos indivíduos ao seu quadro de membros, enquanto nos demais órgãos investigados, os períodos obrigatórios de experiência prévia variam de um a três anos.

Os achados desta pesquisa corroboram ainda com os resultados de Karreman (2002), que constatou que a experiência prática é considerada mais importante em países com sistema jurídico common law do que nos países de sistema civil law (modelo brasileiro), onde os sistemas de educação tendem a ser mais orientados por uma abordagem teórica. $\mathrm{O}$ autor verificou ainda, quanto à educação e treinamento, que a experiência prática nos países analisados caracterizou-se como insuficiente, devido à falta de profissionais qualificados para fornecer suporte aos alunos. Em seus resultados, Crawford et al. (2014) afirmam que os requisitos das IES 2, 3 e 4 são melhor absorvidos pelos acadêmicos em contextos reais de trabalho, no âmbito de uma organização, do que especificamente na universidade. Por fim, para Karreman e Needles (2013) a IES 5 requer que a experiência prática seja obtida pelos indivíduos antes de sua adesão ao órgão de classe, no entanto, no caso brasileiro, os autores relatam que devido ao atual sistema educacional no país, o CFC ainda não foi capaz de introduzir este requisito.

Acerca da Avaliação da Competência Profissional (IES 6) as perspectivas dos Profissionais, Pesquisadores e Coordenadores de Curso é similar. Em síntese, a harmonização global dos requisitos de avaliação traria significativas mudanças para o ambiente nacional de educação contábil e novos métodos avaliativos devem ser debatidos. Para os Coordenadores de PPGCC, no entanto, o contexto brasileiro, de maneira geral, já está em conformidade com a IES 6. Assim, pode-se inferir que a adequação aos preceitos da norma em questão poderia instigar os programas, assim como os docentes, a se capacitarem e adotarem novos métodos avaliativos, em conjunto com os métodos tradicionais, ocasionando uma melhora no processo avaliativo.

Os resultados de Crawford et al. (2014) identificam que os tipos de avaliação são fortemente distintos entre os países e seus respectivos órgãos membros da IFAC, não identificando nenhum parâmetro coerente entre estas entidades. Todavia, Crawford et al. (2010) concluíram que todos os órgãos membros da IFAC deveriam exigir um exame final de estudo de caso, conforme aplica-se no Reino Unido, por exemplo.

Quanto ao Desenvolvimento Profissional Contínuo (IES 7), por unanimidade, os participantes da pesquisa consideram que o CPD, ou educação continuada, deve ser obrigatória para toda classe contábil, sendo sua comprovação devidamente monitorada pelo CFC. Em suas perspectivas, a classe contábil seria mais valorizada perante a opinião pública, tendo em vista que, teoricamente, aqueles profissionais que se mantêm atualizados e em constante aperfeiçoamento profissional, continuam aptos a desempenhar suas funções profissionais ao longo do tempo, com o devido zelo e responsabilidade.

No entanto, conforme resultados de Karreman e Needles (2013) o compliance do sistema educacional brasileiro frente a IES 7 é de nível baixo, tendo em vista que o CFC não exige dos profissionais contábeis a comprovação do desenvolvimento profissional contínuo ao longo dos anos. Nos achados de Peek et al. (2007) e Watty et al. (2014) todos os países investigados exigem a comprovação de Desenvolvimento Profissional Contínuo, conforme previsto pela IES 7, enquanto nos resultados de Phelps e Karreman (2005), somente um órgão profissional situado na Macedônia, entre os 10 
países em desenvolvimento investigados, não possui tal exigência. E ainda, os resultados de Sugahara e Wilson (2013) sugerem que o Desenvolvimento Profissional Contínuo é o segundo tópico mais pesquisado nos estudos internacionais voltados às IES, ficando atrás somente do tópico habilidades profissionais.

\section{CONSIDERAÇÕES FINAIS E RECOMENDAÇÕES}

Este estudo teve como objetivo investigar, sob a ótica dos profissionais, pesquisadores e professores de contabilidade, como as Normas Internacionais de Educação Contábil propostas pelo International Accounting Education Standards Board podem influenciar o ambiente nacional de educação contábil. Para tanto, realizou-se uma pesquisa com abordagem qualitativa, de cunho descritivo, sendo classificada quanto aos seus procedimentos como pesquisa documental, de levantamento e de análise descritiva.

Inicialmente examinou-se as Normas Internacionais de Educação Contábil, a fim de investigar suas especificidades e compreender seus preceitos e requisitos. Esta análise foi dividida em sete tópicos, cada um deles voltado as especificidades de cada uma das IES, de 1 a 7 . Percebe-se que as normas foram elaboradas em torno de uma discussão em nível global, de quais seriam as boas práticas para ensino contábil, sendo estas principle based standards (normas baseadas em princípios), dispondo de um framework robusto, no entanto bastante abrangente, possibilitando que cada jurisdição adapte as IES às suas particularidades regionais. Todavia, para países onde o sistema jurídico dominante seja o commow law, onde as normas são baseadas em regras (rules based standards), como o exemplo do Brasil, o excesso de julgamentos necessários à aplicação das IES gera certa subjetividade na aplicação e operacionalização das normas no contexto nacional.

Em seguida, analisou-se as possíveis influências no ambiente nacional de educação contábil das IES sob a perspectiva dos profissionais, pesquisadores e professores da área, de maneira individualizada e posteriormente entre os grupos nos quais estes foram subdivididos.

Com relação aos Requisitos de Entrada (IES 1), não foram identificadas influências significativas, tendo em vista que na visão dos pesquisados, os requisitos adotados no Brasil contemplam os preceitos idealizados pela IES 1, embora o aspecto seletivo por ela sugerido não tenha eficácia no território brasileiro, devido à superioridade do número de vagas ofertadas frente aos alunos ingressantes e a chamada mercantilização do ensino.

Quanto às Competências Técnicas (IES 2) e Habilidade Profissionais (IES 3), os pesquisados afirmam que o ensino da contabilidade no Brasil possui foco demasiado na técnica, em detrimento do desenvolvimento de aspectos interpessoais, de liderança e comunicação. Desta forma, sugere-se que as principais influências destas normas para o ambiente nacional de educação contábil seriam a implementação de métodos de ensino ativos, como o PBL, debates, estudos de caso e clusters de aprendizado, a reestruturação das diretrizes curriculares dos cursos, ensejando uma formação holística, multidisciplinar e possibilitando a experiência prática em contextos reais, bem como a readaptação dos docentes à nova realidade de ensino e aprendizagem.

Quanto aos Valores Profissionais, Ética e Atitudes (IES 4), embora a maioria dos participantes considere que os aspectos de ceticismo e julgamento profissional não são tratados de maneira suficiente nas Instituições de Ensino, observou-se disparidade nas respostas quando os pesquisados foram indagados à respeito da preocupação do contador com o interesse público e as influências da IES 4 no ambiente nacional de educação contábil. Infere-se que as normas propostas pelo IAESB poderiam influenciar o contexto de ensino contábil brasileiro impulsionando os stakeholders deste processo (órgãos de classe, instituições de ensino e entidades governamentais) a instigar o desenvolvimento dos aspectos éticos, de valores e atitudes na formação acadêmica e profissional dos contabilistas. Na perspectiva de alguns dos pesquisados, este processo poderia beneficiar a classe contábil, no sentido de valorizar o papel da classe contábil frente ao interesse público. 
Acerca da Experiência Prática (IES 5), observou-se perspectivas com diversas particularidades e opiniões distintas. Todavia, contata-se que o sistema de ensino brasileiro não contempla os requisitos da IES 5, principalmente no que tange à comprovação de experiência prática profissional anterior a adesão dos indivíduos aos órgãos de classe e o desenvolvimento desta em contextos reais de ensino. No entanto, não se identificou consenso na perspectiva dos entrevistados no que se refere as possíveis formas de resolver tal problemática. Enquanto alguns pesquisados afirmam que o modelo de laboratórios é suficiente para o desenvolvimento da prática contábil, outros aduzem que estes processos deveriam ser desenvolvidos obrigatoriamente em contextos reais, por meio de estágios realizados em parcerias com empresas idôneas que auxiliem as instituições de ensino neste processo.

Há ainda perspectivas no sentido de que um mix entre estes modelos poderia ser a solução para tal adequação. No mesmo sentido, quanto à comprovação mínima da experiência prática antes da adesão aos órgãos de classe, as opiniões foram bastante distintas. Enquanto alguns participantes mostram-se totalmente a favor da aplicação desta obrigatoriedade, outros se posicionam fortemente contra, devido aos problemas sociais já enfrentados no Brasil, como o desemprego e a dificuldade de inserção do jovem no mercado de trabalho. Todavia, conforme identificou-se na literatura, esta é uma tendência mundial e poucos países ainda não são adeptos a tal procedimento. Embora o Brasil possua suas particularidades sociais, devem ser debatidas possíveis soluções para adequação do ambiente nacional de educação contábil frente a IES 5.

Com relação à Avaliação da Competência Profissional (IES 6), para os participantes, uma harmonização global dos requisitos avaliativos é vista com bons olhos, respeitando-se as particularidades de cada região. As principais influências seriam a impulsão dos programas de educação contábil a estimular seus docentes para atualizações e aperfeiçoamentos de docência, assim como a aplicação de um leque variado de métodos avaliativos, principalmente no que se refere à avaliação da experiência prática. No Brasil, tem-se difundida a avaliação da experiência prática por meio da abordagem baseada em inputs, que se baseia em registros de frequência e tempo gasto nas atividades, enquanto a abordagem baseada em outputs, com o intuito de medir os resultados de aprendizagem ou competências desenvolvidas com a experiência prática é pouco, ou quase nada disseminada.

Já com relação ao Desenvolvimento Profissional Contínuo (IES 7), a perspectiva dos pesquisados é unânime no sentido de que a influência desta norma em implementar a Educação Continuada obrigatória para toda classe contábil, sendo esta devidamente monitorada pelos órgãos de classe, aplicando-se as devidas sanções necessárias para os indivíduos que não cumpram tais determinações. Novamente os participantes afirmam que a adoção destes preceitos poderia culminar em uma classe contábil mais valorizada perante a opinião pública.

Assim como os resultados de Karreman (2002), Phelps e Karreman (2005), Stainbank e Ramatho (2007), Karreman e Needles (2013) e Helliar (2013), os resultados desta pesquisa demonstram que é possível utilizar um modelo para o ensino de contabilidade em nível global, o que não restringe que as diferentes jurisdições realizem adaptações ao framework do IAESB para contemplar suas diferenças locais e regionais, desde que respeitados os princípios propostos pelas IES, que devem ser vistas como guidelines e não como imposições.

De maneira geral, frente a percepção dos profissionais, pesquisadores e professores de contabilidade quanto às possíveis influências das Normas Internacionais de Educação Contábil, percebe-se que enquanto a categoria Requisitos de Entrada (IES 1), de fato, parece estar suficientemente contemplada no ambiente nacional de educação contábil, a Experiência Prática (IES 5) e o Desenvolvimento Profissional Contínuo (IES 7), por sua vez, possivelmente causarão maiores influências no contexto brasileiro, quando da adequação as Normas Internacionais de Educação Contábil. Por fim, com relação as categorias Competências Técnicas (IES 2), Habilidade Profissionais (IES 3), Valores 
Profissionais, Ética e Atitudes (IES 4) e Avaliação da Competência Profissional (IES 6), evidencia-se uma adequação parcial do ambiente de educação contábil brasileiro, no entanto, conforme identificado, algumas particularidades ainda precisam ser ajustadas.

Ademais, a partir das limitações de pesquisa elencadas e do referencial teórico explorado, apresentam-se recomendações e insights para a realização de estudos futuros sobre a temática investigada. Diversas vertentes de estudo mais aprofundados em cada uma das IES, de maneira específica, podem ser elaborados. Uma possibilidade de pesquisa consiste em analisar as diretrizes curriculares de instituições de ensino superior frente às áreas de competência dispostas na IES 2. Todas as áreas são contempladas? Existe foco em algumas áreas em detrimento de outras? Ainda com relação a IES 2, poder-se-ia examinar a perspectiva de egressos e/ou estudantes do último período do curso de graduação em Ciências Contábeis, referente as áreas de competência desenvolvidas em sua formação. Seu curso lhe possibilitou uma formação holística conforme prevê a IES 2, inter-relacionando técnica, habilidades profissionais e aspectos éticos?

No que se refere a IES 3, pode-se analisar as diretrizes curriculares de instituições de ensino superior frente às áreas de competência dispostas na IES 3. Todas as áreas são contempladas? As diretrizes brasileiras realmente priorizam competências técnicas em detrimento do desenvolvimento de habilidades interpessoais? Outro objetivo poderia focarno exame da perspectiva de professores de contabilidade quanto ao desenvolvimento de aspectos intelectuais, interpessoais e de comunicação, pessoais e organizacionais na formação de acadêmicos. Quais métodos de ensino são mais propícios para tal? Que estratégias adotar?

A IES 4, do mesmo modo, possibilita a realização de pesquisas como analisar as diretrizes curriculares dos cursos de contabilidade em instituições de ensino superior frente as áreas de competência dispostas na IES 4. Todas as áreas são contempladas? Os aspectos de ceticismo, julgamento profissional, princípios éticos e compromisso com o interesse públicos são todos tratados de maneira equivalente durante a formação dos acadêmicos de Ciências Contábeis? Outra possibilidade consiste em investigar na perspectiva de professores e/ou acadêmicos de Ciências Contábeis se os cinco Princípios Éticos fundamentais relatados pelo IESBA (2014), Integridade, Objetividade, Competência e Diligência Profissional, Confidencialidade e Comportamento Profissional são devidamente difundidos na formação dos acadêmicos.

Com relação a IES 5, poder-se-ia investigar se a Experiência Prática adquirida pelos estudantes durante sua formação contábil no Brasil é suficiente para potencializar as Competências Técnicas (IES 2), Habilidades Profissionais (IES 3) e Valores Profissionais, Ética e Atitudes (IES 4) necessários para que este exerça as atividades e atribuições de um contador, conforme prevê a IES 5. Uma segunda possibilidade seria comparar os modelos de experiência prática instituídos durante a formação de alunos de contabilidade em outros países frente aos modelos utilizados no Brasil. Quais as principais diferenças percebidas? Nestes países a comprovação de experiência prática é obrigatória antes da adesão dos indivíduos aos órgãos de classe? O que o modelo brasileiro poderia absorver dos modelos investigados para melhorar sua adequação a IES 5? Ainda com relação a IES 5, seria possível analisar as abordagens para medir a experiência prática utilizada por professores e/ou programas de educação contábil no Brasil. Qual abordagem é mais utilizada (baseada em inputs, outputs ou mista)? Quais as consequências disto para o processo de ensino e aprendizagem, bem como, a formação dos alunos de Ciências Contábeis?

No que se refere a IES 6 e avaliação de competências técnicas, sugere-se investigar quais os métodos de avaliação e ensino-aprendizagem mais utilizados em cursos de Ciências Contábeis. Novos métodos avaliativos e de ensino estão sendo utilizados diante do panorama de harmonização da educação contábil em nível internacional? Métodos de ensino ativos como PBL estão sendo utilizados nos cursos de Ciências Contábeis? Como a utilização de métodos ativos podem auxiliar a formação do acadêmico em Ciências Contábeis? Quais disciplinas são mais propícias para aplicação 
de tais métodos? A perspectiva dos acadêmicos é a mesma dos professores com relação a utilização destas técnicas?

Por fim, no que tange a IES 7, sugere-se analisar a perspectiva dos profissionais contábeis, acadêmicos e professores com relação a implementação da obrigatoriedade da Educação Continuada para todos os integrantes da categoria. Quais possíveis consequências isso traria para classe? Quais os melhores formatos para se propiciar a Educação Continuada e de que forma monitorá-la?

\section{REFERÊNCIAS}

Abbasi, N. (2013). Competency approach to accounting education: a global view. Journal of Finance $\mathcal{E}$ Accountancy, 13(1), 1-19.

Boyce, G. (2002). Now and then: revolutions in higher learning. Critical Perspective on Accounting, $13(1), 575-601$.

Boyce, G. (2004). Critical accounting education: teaching and learning outside the circle. Critical Perspective on Accounting, 15(1), 565-586.

Crawford, L., Hellliar, C., Monk, E., \& Veneziani, M (2014). International Accounting Education Standards Board: Organisational legitimacy within the field of professional accountancy education. Accounting Forum, 38(1), 67-89.

Crawford, L., Hellliar, C., Monk, E., Mina, M., Teodori, C., Veneziani, M., Wanyama, S., \& Falgi, K (2010). IES compliance and the knowledge, skills and values of IES 2, 3 and 4, IAAER/ACCA Research Project, nov., London: ACCA.

Flick, U. (2009). An introduction to qualitative research. 4. ed. Thousand Oaks: SAGE Publications.

Helliar, C. (2013). The global challenge for accounting education. Accounting Education: an international journal, 22(6). 510-521.

Howieson, B. (2003). Accounting practice in the new millennium: is accounting education ready to meet the challenge? The British Accounting Review, 35(1), 69-103.

Humphrey, C., Loft, A., \& Woods, M (2009). The global audit profession and the international financial architecture. Accounting, Organizations and Society, 34(1), 810-825.

IAESB - International Accounting Education Standard Board (2006). Approaches to the Development and Maintenance of Professional Values, Ethics and Attitudes. Disponível em: < http://tinyurl.com/IAESB2006>. Acesso em: 19/05/2015.

IAESB - International Accounting Education Standard Board (2012). Update: International Education Standards Revision Project. Disponível em: < http://tinyurl.com/IAESB2012>. Acesso em: 19/05/2015.

IAESB - International Accounting Education Standard Board (2013a). International Accounting Education Standards Board Fact Sheet. Disponível em: <http://tinyurl.com/FactSheet2013aa $>$. Acesso em: 05/05/2015.

IAESB - International Accounting Education Standard Board (2013b). IAESB: 2014 - 2016 Strategy and Work Plan. Disponível em: <http://tinyurl.com/StrategyAndWorkPlan>. Acesso em: 19/05/2015.

IAESB - International Accounting Education Standard Board (2014a). Handbook of International Education Pronouncements. Disponível em: < http://tinyurl.com/HIEP2014a>. Acesso em: 22/05/2015.

IAESB - International Accounting Education Standard Board (2014b). Proposed Framework for IES. Disponível em: < http://tinyurl.com/hlnpkb8>. Acesso em: 24/05/2015.

IESBA - International Ethics Standards Board for Accountants (2014). Handbook of the Code of Ethics for Professional Accountants. New York, New York, 2014. 
IFAC - International Federation of Accountants (2012). Statements of Membership Obligations. Disponível em: <http://tinyurl.com/zf29k8l>. Acesso em: 19/05/2015.

Karreman, G. H. (2002). Impact of Globalisation on Accountancy Education, London, International Accounting Standards Committee Foundation - IASCF. Disponível em: $<$ http://tinyurl.com/j4w8vdz>. Acesso em: 03/07/2015.

Karreman, G. H., \& Needles, B. E (2013). Global Accountancy Education Recognition Study 2012, National Association of State Boards of Accountancy. Disponível em: $<$ http://nasba.org/files/2013/08/GAER_2012_Study_Final.pdf $>$. Acesso em: 03/07/2015.

Maxwell, J. A. (2013). Qualitative research design: an interactive approach, 3, Thousand Oaks: SAGE Publications.

Olsen, W. K. (2004). Triangulation in Social Research: qualitative and quantitative methods. In: Holborn, M. Developments in Sociology. Ormskirk: Causeway Press.

Peek, L., Roxas, M., Peek, G., Mcgraw, E., Robichaud, Y., \& Villarreal, J. C. (2007). NAFTA Professional Mutual Recognition Agreements: Comparative Analysis of Accountancy Certification and Licensure. Global Perspectives on Accounting Education, 4(1), 1-24.

Phelps, R. W., \& Karreman, G. (2005). Report on the results of the Global Accounting Education Benchmarking pilot project, Washington. Disponível em: $<$ http://pdf.usaid.gov/pdf_docs/pnadg707.pdf >. Acesso em: 03/07/2015.

Saravanamuthu, K., \& Tinker, T. (2002). The university in the new corporate world. Critical Perspective On Accounting, 13(1), 545-554.

Stainbank, L. J., \& Ramatho, G. (2008). Professional accountancy education in selected ECSAFA countries. Meditari Accountancy Research, 16(2), 153-173.

Sugahara, S., \& Wilson, R (2013). Discourse surrounding the IES for professional accountants. Accounting Education: an international jornal, 22(3), 213-232.

Sugahara, S., Boland, G. (2011). Effects of exposure to the IES on perceived importance of the global harmonization of accounting education among japanese academics. Advances in Accounting and Advances in International Accounting, 27(1), 382-389.

Watty, K., Sugahara, S., Abayadeera, N., Perera, L., Mckay, J. (2014). Towards a global model of accounting education. Accounting Research Journal, v. 27(3), 286-300. 